\title{
The cultural dilemma in the process of uniting Chinese and Western medicine from 1940 to 1950
}

\author{
Qing Liu(1)
}

\author{
Correspondence: \\ liuqing_helen@163.com \\ Department of Foreign Studies, \\ South China Agricultural University, \\ Wushan Street No. 483, Guangzhou \\ 510642, People's Republic of China
}

\begin{abstract}
This article examines the medical policy discourse of the Communist Party of China (CPC) between 1940 and 1950 that witnessed the preliminary achievement of the policy of cooperation between Chinese and Western medicine and the eventual definitive policy of uniting Chinese and Western medicine. The CPC's promotion is commonly considered the key to the unusual success of traditional Chinese medicine in modern China. However, rather than taking the success of traditional Chinese medicine as deliberately planned political strategies and overstating the agency of the CPC, this study borrows the sociological notion of habitus and combines it with a critical discourse analysis (CDA) framework. From this perspective, the discourse of medical policy is taken as a continuing and recontextualized attitude and collective memory concerning the tension between the traditional and the modern, the Chinese and the Western.
\end{abstract}

Keywords: Habitus, Traditional Chinese medicine, Western medicine, Cultural ideology

\section{Introduction}

It is hard to find a modern country similar to China in which traditional medicine still plays such a crucial role in the national health system. Unlike the more common scenario in which traditional medicine eventually evolves into a kind of folk, alternative, or complementary medicine, traditional and modern medicine have developed together in China, and there is a new branch of medicine that combines traditional Chinese medicine and Western medicine. From this unique phenomenon, it is natural to ask what factors facilitated the decision to place traditional Chinese medicine in such a central position alongside modern or Western medicine. Historians have investigated the process of the development of traditional Chinese medicine and its conflict with Western medicine in a number of comprehensive works (e.g., Li and Cheng 1987; Li 1998; Jia 1978; Zhao 1989). Other researchers have tended to focus on the medical policies of the Communist Party of China (CPC) and have taken its policies as the key to the success of traditional Chinese medicine. They have investigated the great value of traditional Chinese medicine for the Red Army during difficult times in the civil war, such as the encirclement and suppression period when no medical resources were available, and have recorded how the Red Army made the best of its limited resources and

(c) The Author(s). 2019 Open Access This article is distributed under the terms of the Creative Commons Attribution 4.0 International License (http://creativecommons.org/licenses/by/4.0/), which permits unrestricted use, distribution, and reproduction in any medium, provided you give appropriate credit to the original author(s) and the source, provide a link to the Creative Commons license, and indicate if changes were made. 
realized the institutionalization of traditional Chinese medicine after 1949 (Li 1986; Wang et al. 2011; Wen 2010; Zhu 2010).

In the West, the history of traditional Chinese medicine has been understood through works by Western researchers. What is more influential than an elaborate overview of the history of traditional Chinese medicine (e.g., Sivin 1987; Unschuld, 1985) is the research exploring the problems of traditional Chinese medicine under a cultural framework. For instance, Farquhar (1994) investigates the framework of traditional Chinese medicine by presenting the logic of diagnosis and treatment from the internal perspectives of doctors and scholars, and Scheid (2002) offers a perspicacious perspective on pluralism in Chinese medical practices. Another type of study, represented by Croizier (1968) and Taylor (2005), pays much attention to the socio-political contexts of the social practice of traditional Chinese medicine. Croizier attempts to illustrate the tensions between maintaining a national identity and learning Western science in modern China and the intellectual attitudes toward "science, progress, modernity, traditional authority and cultural nationalism" $(1968,8)$ through the lens of traditional Chinese medicine. Taylor's study describes the transformation of traditional Chinese medicine between 1945 and 1963 from a marginalized position to a central one under the policies of the CPC. Compared with local studies of the CPC's medical policies such as uniting Chinese and Western medicine (e.g., Fan 2014), Taylor goes further by investigating the ideological factors beneath the social practices. He makes a strong claim that one of the primary reasons Chinese medicine gained this status was that it matched the ideals of the Communist Revolution. Thus, political and economic considerations, not therapeutic ones, were the greatest driving force in the development of traditional Chinese medicine.

There are problems with the studies of socio-political factors conducted by local and Western researchers. Although it is claimed that the success of traditional Chinese medicine was not a mere product of economic and political conditions, especially since Western medicine was unavailable in the border regions, much of the discussion in works by local researchers centers around the CPC's efforts to develop traditional Chinese medicine without asking why. However, in Western studies that pay attention to the interaction of political power in the process of traditional Chinese medicine's development (e.g., Croizier 1968; Lampton 1974; Taylor 2005), the agency of the CPC is overstated, as if the success of traditional Chinese medicine was deliberately planned through the CPC's political strategies. For instance, Taylor (2005) makes an interesting observation that the practice of promoting traditional Chinese medicine was coherent with the nature of nationalism in the CPC's ideological framework, but he fails to explore the motivation behind this nationalism and its manifestation in the longer history of China. In other words, the connection between sociopolitical factors, historical contexts, and certain historical turning points is often overlooked.

This study therefore borrows the notion of habitus from Bourdieu's work and suggests that the CPC's social practice of traditional Chinese medicine is in large part a habitus. This means, in contrast to Taylor's criticism, that the practice is "not a continuing tradition of the past" $(2005,1)$. Rather, it is a continuing and recontextualized perspective, attitude, or collective memory concerning the tension between the traditional and the modern, the Chinese and the Western. This study focuses on the period from 1940 to 1950, a time that witnessed the preliminary achievement of the policy of cooperation between Chinese and Western medicine and the eventual definitive policy of uniting 
Chinese and Western medicine. In particular, the study explores the underlying cultural ideological factors from the perspective of habitus. Here, the term "cultural habitus" refers to the dispositions shaped by the whole process of cultural and ideological dilemma, or more specifically the tension between Chinese nationalism and Western culture, the traditional and the modern. I argue that not only the historical realities of the dilemma are included, but more significantly, the process of how the dilemma is proposed, approached, and tentatively solved in discourse is considered as well. This tension has long been a central topic in Chinese nationalism studies. For instance, Bai (1992) concludes that the Chinese attitude toward Western modern culture is significantly different than other post-colonies' attitudes. In China, nationalism and Western modernization are essentially fighting against each other rather than promoting each other. It is believed that this thought pattern has been strengthened generation after generation and has been anchored or entrenched in the framework of Chinese cultural ideology. For a topic as sensitive as traditional Chinese medicine-sensitive since, to a large degree, it embodies Chinese traditional culture-this cultural habitus will inevitably play an important role. Therefore, the current study investigates the way such a dilemma is recontextualized in the policy discourse of traditional Chinese medicine and the process of how the dilemma is proposed, approached, and tentatively solved in discourse.

\section{Habitus and critical discourse analysis (CDA)}

Habitus is the core concept in this study and is used to explore the pattern of medical policy discourse and to seek answers to significant questions about the motivations and deep cultural structures underlying the so-called political strategy or ideology. In the concept of habitus, the response is not a strategic calculation, but is considered in relation to "objective potentialities, immediately inscribed in the present, things to do or not to do, things to say or not to say, in relation to a probable, 'upcoming' future" (Bourdieu 1990, 53). The strategies are not "an explicit, conscious project" either but are a pursuit of the "objective potentialities" immediately given in the immediate present' (Bourdieu and Wacquant 1992, 128). This assumption helps to overcome the division between objectivism and subjectivism, and for this study, it also helps transcend the limitations of the literature on the CPC's medical policy-either the overstatement of the CPC's ideological strategy or the tendency of economic determinism. For example, it would be inappropriate to relate the promotion of traditional Chinese medicine to nationalism in the CPC's ideological framework without contextualizing it. During the formative years of the policy promoting traditional Chinese medicine, China was fighting imperialism and struggling for liberation. In this context, Western medicine as a product of Western modernity would naturally become a symbol in opposition to indigenous traditions, which the intellectuals or political elites needed to prudently address. As emphasized by Bourdieu, habitus is, to some degree, structured by history: "The habitus, a product of history, produces individual and collective practices-more history-in accordance with the schemes generated by history. It ensures the active presence of past experiences, which, deposited in each organism in the form of schemes of perception, thought and action, tend to guarantee the 'correctness' of practices and their constancy over time, more reliably than all formal rules and explicit norms" $(1990,54)$. 
The historical perspective in the current article is not restricted to the medical conditions of the Red Army during wartime that researchers have extensively discussed; it also encompasses the "practical schemata of perception" (Bourdieu and Wacquant 1992, 139), or the pattern of cultural ideology formed after the Sino-Japanese War (1894-1895), and the continuing debate between the frameworks of Chinese and Western, traditional and modern, and scientific and moral. As an ancient country that developed on its own trajectory for thousands of years, transformation from the outside or movement toward westernization in an emergent situation such as war would probably bring chaos and contradictions in the deep structure of the ideology of China. In addition, the pattern is profoundly framed by "early experience" (Bourdieu 1990, 54), which refers here to the Sino-Japanese War (1894-1895), the collective memory of humiliation from the terrible defeat by the newly emerging capitalism, the fear of the hegemony of an outside culture over Confucianism, and so on. This dispute has continued, been strengthened, and restructured in China's long history as an "open system of dispositions that is constantly subjected to experiences," and therefore "constantly affected by them in a way that either reinforces or modifies its structures" (Bourdieu and Wacquant 1992, 133).

In this article, habitus as a sociological notion is borrowed and tentatively combined with a CDA framework. CDA generally assumes a dialectical relationship between particular discursive practices and the situations, institutions, and social structures in which they are embedded, which means that discourse is constituting discursive and non-discursive social practices and meanwhile is constituted by them (Wodak 2001, 66). The use of the notion of habitus in CDA studies helps relate individual dispositions to social structures, thus "enabling an explanation of the persistence and reproduction of social inequality" (Forchtner and Schneickert 2016). This concept is utilized in Wodak et al. (2009) study of the Austrian national character and taken as cultural patterns anchored in the body of nations. In another study on political discourse, the professional habitus of politicians in the European Parliament is understood as "an incorporated, subconsciously effective, stable strategy, directing the perception and action of actors ... which distinguishes one profession from another and enables differentiation" (Wodak 2011, 12). In Unger's (2013) study of the use of the Scots language, the notion of linguistic habitus is borrowed to explore the relationship between language and power. In this way, the construction of discourse is investigated through scrutinizing the habitus embedded in the individual or collective body. In this study, the theories of CDA (van Dijk 1998; Fairclough 1989, 1992; Chouliaraki and Fairclough 1999; Wodak 2001, Wodak et al., 2009, Wodak and Fairclough, 2010) are utilized. As for the more specific linguistic tools, word meaning and wording, metaphor, and systemic functional grammar are utilized in detailed analysis.

\section{The history of traditional Chinese medicine and medical policy}

A brief review of the history of the importation of Western medicine, its rapid development and hegemonic position, and the CPC's promotion of traditional Chinese medicine to progress alongside its Western counterpart is needed to better understand the patterns of social practice and political strategy. European Christian missionaries brought Western medicine to China in the sixteenth century. However, the real crisis 
for traditional Chinese medicine began after the Sino-Japanese War (1894-1895). That tragic defeat shocked the entire nation and forced indigenous intellectuals to reflect on their ideological foundations, which had been solid and strengthened for thousands of years. It also started the longstanding debate between tradition and modernity, Confucianism morality and science, and the Chinese and the Western. Deeply embedded in philosophical theories such as "yin-yang" and "harmony between man and nature," traditional Chinese medicine was categorized as a symbol of traditional culture and was thus easily placed in opposition to the advanced and modern. The hegemony of the scientific framework reached its peak with the May Fourth Movement in which things that did not match the scientific framework were fiercely criticized and marginalized and were urged to be discarded.

Under the regime of the Nationalist Party, along with the modernization process of the health care system toward a Western model, traditional Chinese medicine was further marginalized. At the first Central Health Committee meeting in 1929, no doctors of traditional Chinese medicine were invited to serve as committee members, proposals about abolishing traditional Chinese medicine were discussed, and one of the most important reasons given for abolishing traditional Chinese medicine was that it lacked solid, scientific foundational theories and therefore would inhibit the modernization and scientification process of medicine in China. Traditional Chinese medicine was removed from the medical education system, and practitioners were excluded from medical institutions in the central government and local government bodies. The number of doctors practicing traditional Chinese medicine dropped from 800,000 to 500,000 between 1911 and 1949. It can thus be concluded that framing traditional Chinese medicine politically was not a pioneering and strategic plan by the $\mathrm{CPC}$; instead, it was taken as a symbol of the traditional and backward and thus an obstacle to modernization and scientification under the regime of the Nationalists. The social practices of traditional Chinese medicine differed between the CPC and the Nationalists, which may have been caused by their different attitudes and perspectives toward the Chinese path to modernization and their relationship to Western capitalism. In addition, a crucial difference was the therapeutic efficiency of traditional Chinese medicine during the war, especially during the civil war against the Nationalists, as many studies have discussed extensively (e.g., Fan 2014; Li 1986; Wang and Tao 1996; Wen 2010; Taylor 2005). During that time, the Communist revolutionaries' bases faced severe shortages of medicine and doctors, and since their bases were located in remote areas and were blockaded by the Nationalists, the transportation of medical supplies was impossible. Under these circumstances, the CPC optimized their available medical resources-doctors of the traditional Chinese medicine popular in the countryside, along with herbal medicine that could be found in forests and mountains. Herbs were used as a replacement for Western medicines to cure injured soldiers. For example, Xiao Chaihu was used in lieu of quinine and aspirin. Further efforts were made by setting up pharmaceutical factories to make herbal ingredients into various medicines.

Although it is suggested here that the habitus of the CPC was more or less a product of history, to determine what this habitus was we have to relate "the social conditions in which the habitus that generated them was constituted ... through the scientific work of performing the interrelationship of these two states of the social world that the 
habitus performs, while concealing it, in and through practice" (Bourdieu 1990, 56). Clarifying this issue would be impossible in this discourse study. This study focuses on the patterns of policy discourse. One of the most significant characteristics of the discourse is the pattern of duality between the Chinese and the Western. Take references to traditional Chinese medicine and its Western counterpart as a typical example. The names for traditional Chinese medicine before the CPC's regime included "national medicine," "ancient medicine," and "old medicine." In the CPC's discourse, the most common and standard name is "Chinese medicine," which is differentiated from its counterpart "Western medicine." It is suggested this change meant that traditional Chinese medicine was "moved from a marginally accepted sideline of the national health care system to an essential part of it" (Taylor 2005, 13). This dualism is also illustrated by medical policy slogans. The three slogans showing the focus of the CPC's medical work in different periods are "cooperation of Chinese and Western medicines" (1945-50), "unification of Chinese and Western medicines" (1950-58), and "integration of Chinese and Western medicine" (1958-present). Comparing the semantics of the three keywords "cooperation," "unification," and "integration," we can infer that the relationship between Chinese and Western medicine was growing increasingly close. Compared to "cooperation," which is a more neutral word, "unification" exhibits more political connotations and is also a frequently used word in the CPC's political discourse. The use of the word "integration" indicates a higher standard for the medical work of traditional Chinese medicine and Western medicine, and an intention to ultimately eliminate the distinction between these two approaches. In fact, Chairman Mao made a statement about this intention in a political bureau meeting in 1953: "In the future, there should be only one medicine, not two separate medicines. There ought to be only one integrated medicine guided by the laws of dialectical materialism" (Mao 2013).

\section{Data description}

In the current study, the data for analysis include two of Mao's speeches-“On New Democracy" in 1940 and the "United Front in Cultural Work" in 1944, and texts from the first National Health Conference in 1950. These texts were selected because the years from 1940 to 1950 witnessed a progression from the tentative policy of cooperation between Chinese and Western medicine to the eventual definitive policy of uniting Chinese and Western medicine. Additionally, each selected text constructs the discourse of medical policy and social practice concerning medical development in different ways. First, "On New Democracy," originally a long speech by Mao, was published on January 19, 1940, in the debut issue of the journal Chinese Culture. Subsequently, the first and second National Medicine Congresses were held in the Shaanxi-Gansu-Ningxia border region in 1940 and 1941 respectively, in which the feasibility of the scientification of Chinese medicine and the cooperation between Chinese and Western medicine were widely discussed. Second, Mao delivered the speech "United Front in Cultural Work" at a conference of cultural educational workers of the Border Region on October 30, 1944. It is believed that in 1941 cooperation between Chinese and Western medicine was still in its conceptual phase, but substantial progress was achieved after Mao's 1944 speech (Zhu 2010). In the speech, Mao solidifies 
the policy of cooperation between Chinese and Western medicine. After the speech, a series of symposia were organized in which doctors of traditional Chinese medicine and Western medicine were invited to discuss the development and cooperation of these two approaches to medicine. Thus, pertinent proposals were pushed through that covered various aspects, including the improvement of Chinese doctors' status and pay, the establishment of schools for Chinese medicine, and the utilization of Chinese medicinal materials. The slogans of "scientification of Chinese medicine" and "sinization of Western medicine" were created. Therefore, a technical issue of medical development was turned into a political task in order to efficiently dissolve the prejudice and hostility between Chinese and Western medicine (Zhu 2010). Third, the first National Health Conference was held in Beijing in 1950. The texts analyzed in the study included a report by Health Minister Li Dequan, reports by Central Military Commission Health Minister He Cheng, and the closing statement by the Central Military Commission Vice Health Minister Fu Lianzhang. At the conference, the policy on unifying Chinese and Western medicine was finally formalized as the core principle of medical work in the People's Republic of China, together with the policies of "serving the workers, peasants, and soldiers," and "prevention first" (CQMWA 1950). In 1951, a series of concrete measures on the unification of Chinese and Western medicine were written into the proposal passed by the Ministry of Health.

However, there may be a major problem regarding the type of data selected for analysis. If it is acceptable to classify the texts from the first National Health Conference into the discourse of medical policy, then Mao's two speeches seem to be a completely different type of data. In fact, no text by Mao specifically on medical development can be found during that period; only a few words in conversations and inscriptions are recorded. In studies on medical policy, Mao's discourses on the construction of socialist culture are often taken as data for analysis. In fact, it seems to be an already acknowledged premise that for the most part all Chinese medical work under the CPC can be attributed to Mao Zedong, and his ideological framework has been commonly defined as the framework for the development of Chinese medicine in the academic world. For instance, national symposiums on Mao's medical ideology have been held since 1993, and the ideology of Chinese medicine has been an important branch of research relating to Mao's ideology (e.g., Wang and Tao 1996; Liu 2014; Ding 1993; Sun 1998). It can only be tentatively speculated here why Mao's discourse on cultural ideology is equated with medical policy discourse. This equation may be explained by the genre chain in the political context of that time. Before the medical policies were formulated, policy makers, either in the health ministry or local governments, had to study the general political framework, of which Mao's discourse of cultural ideology was the most important source. In this way, the medical policy is coherent with the general sociopolitical ideology framework, and thus, Mao's words on cultural construction are recontextualized in the medical policy formulated by the health ministry and local governments.

Taking the speech "On New Democracy" as an example, Mao defined the three basic principles of socialist culture as national, scientific and for the general masses. Being national means that "it opposes imperialist oppression and upholds the dignity and independence of the Chinese nation" (Mao 1986). The socialist culture is scientific in that it is opposed to "all feudal and superstitious ideas, it stands for seeking truth from facts, for 
objective truth and for the unity of theory and practice" (Mao 1986). It is for the general masses since it "should serve the toiling masses of workers and peasants who make up more than 90 percent of the nation's population and should gradually become their very own" (Mao 1986). In addition, in this speech, Mao specifically addresses how to handle the relationship between Chinese and Western cultures and between traditional and modern cultures, and he was clearly opposed to the trend of total westernization. In the first National Medicine Congress in 1940, the claim "the cultural heritage should be inherited, developed while discarded and transformed" was made (Zhu 2010), which is a recontextualization of Mao's conclusions in his speech about the relationship between Chinese and Western culture. In some studies, his words "essence and dross" and "criticize and inherit" are pulled from the speech, and considered not only as the guideline for medical development but also as a fundamental element of the theory for the modernization of traditional Chinese medicine (Fan 2014). ${ }^{1}$

\section{Data analysis}

\section{"Western" or "scientific"?}

This section investigates the meaning of the word "science" and its use in the data, and explores the way it constructs the cultural ideology behind medical policy discourse. The equivalent of "science" in contemporary Chinese is ke xue, which took the place of the word ge zhi in 1900. It is generally believed by researchers that the connotation of ke xue is very different from that of science. For the convenience of the reader, in the following section, I use "science" as a uniform name for both science in a Western context and ke xue. The first definition of science in the Oxford English Dictionary is "the intellectual and practical activity encompassing the systematic study of the structure and behavior of the physical and natural world through observation and experiment." It is known that the range of usage of the term "science" has increasingly narrowed. As Williams observes, "Scientific, scientific method and scientific truth became specialized to the successful methods of the natural sciences, primarily physics, chemistry and biology ... it was the hard objective character of the material and the method, which in these areas went together, which was taken as defining" (1983, 279). Williams further concludes that the specialization of science is "more complete in English than in most comparable languages" $(1983,279)$. Indeed, the interpretation of "science" in the late Qing dynasty was not confined to the innate laws of things but was by and large related to themes such as saving the nation, modernization, and cultural differences (Wang 2004). For instance, previous studies have shown that in the early twentieth century in China, "science" was often taken as the opposition of superstition, and these two words are frequently mentioned in the same text (Jin and Liu 2009). Such emphasis on the function of suppressing superstition is plainly seen in the use of "science" by Liang Qichao, the foremost Chinese intellectual leader in the first two decades of the twentieth century: "As science thrives day by day, superstition is on the decline" (Liang 1989). During the May Fourth Movement, science became a powerful and controversial concept. Researchers often focus on the use of the term "science" in this period. For example, it has been shown that Chen Duxiu, the leader of the movement against tradition and chief editor of New Youth, the most influential journal during the May Fourth Movement, frequently used "science" as a resistance force in the revolution and 
rarely used the word with its standard definition (Wang 2004). Additionally, Jin Guantao and Liu Qingfeng (2009) adopt a corpus method to study the use of "science" in New Youth, and find that the four most common connotations of "science" are as follows: (1) its rational spirit and its function as the opposition to superstition and nonrationality; (2) its subjects and theories; (3) its technologies that can facilitate the strength of the nation; (4) Marxism or scientific socialism. The authors believe that even today Chinese people often use the term "science" with an emphasis on moral and ideological functions; some connotations cannot be found in Western contextual definitions, such as advanced productive force (Jin and Liu 2009).

The following example 1 explains one of the three basic properties of socialist culture-being scientific. What science is and what it opposes are paraphrased, realized by two antonymous verbs "object" and "claim." The connotation of "science" not only includes "seeking truth from facts, for objective truth and for the unity of theory and practice" but also includes the struggle against "all feudal and superstitious ideas" (Mao 1986). Such use is not rare in the CPC ideology discourse since fighting against feudalism and superstition were urgent tasks for the CPC in constructing its new culture, considering the fact that some of the leading members of the party were peasants deeply embedded within the culture of feudal society. When it came to the problem of rural medical conditions, science was exploited in the same way by framing the issue as the prevalence of superstition and lack of science, as in example 2.

Two more common uses of "science" include equating it with technology and references to Western medicine. For instance, the adjective "scientific" in examples 3, 4, and 6 means "Western," since the noun phrase "scientific medicine" refers to Western medicine, and "scientific doctor" refers to a Western doctor. In example 3, in the theme position, the conjunction "before" indicates the superiority of Western medicine over Chinese medicine, and the word "scientific" highlights the "unscientific" part of Chinese medicine. In the first clause, China is in a passive position being imported, implying the hegemonic role of Western medicine. There is thus the question of why the word "Western" is not used. The reluctance to use "Western" can also be found in example 5. A dichotomy between Chinese and Western medicine is constructed when social actions such as cooperation, building a united front, and fighting against superstition are mentioned. However, in regard to more abstract aspects such as the theoretical reference to the transformation of medicine, the regular paralleled structure "Chinese and Western medicine" is changed into an unparalleled one-"Sinization" and "scientification." In example 6, the complicated attitudes toward references to the West and Western modern culture are reflected in the fact that the names "Western medicine" and "scientific medicine" are changed back and forth. In the first sentence, the reference changes twice, from "Western" to "scientific" and then changed back to "Western." Using "Western" in the topic suggests this is the official and popularized reference. Using "scientific" in the first clause defines the initial name, and in the second clause "Western" is again used by defining it as a customary name according to the location of its birth. In the second sentence "scientific" is used twice with positive evaluation of the connotations. In the last sentence, with the changed reference "Western" and the transition "however," the evaluation becomes negative. Here the connotation of "Western" is more than the location; it is closely related to the ideology of capitalism. From this example we can suppose that the reason the phrase "Western medicine" is 
cautiously used is because it is difficult to separate the meaning of the spatial location from the social ideology, which was also a major task for CPC culture construction.

1. New democratic culture is scientific. Opposed as it is to all feudal and superstitious ideas, it stands for seeking truth from facts, for objective truth and for the unity of theory and practice (Mao 1986, 398).

On New Democracy (1940)

2. On the one hand, in the vast area of countryside, there is no scientific medicine, but only the folk medical treatment for heatstroke and childbirth. Even worse, there are neither doctors nor medicine at all in some remote places, where residents can only pray to Buddha for blessings and help (CQMWA 1950, 16).

Reports of the First National Health Conference (1950)

3. Before scientific medicine was imported to China, Chinese people were completely relying on traditional Chinese medicine (CQMWA 1950, 22)..

Reports of the First National Health Conference (1950)

4. Although there are some scientific doctors in China, they are concentrated in cities. Traditional Chinese medicine is still the major medical resource in rural areas, thus the present problem cannot be solved without participation of Chinese doctors in medical work (CQMWA 1950, 22)..

Reports of the First National Health Conference (1950)

5. In the issue of cooperation between Chinese and Western medicine, we cannot only focus on one side and overlook the other. We should realize the scientification of Chinese medicine, and Sinization of Western medicine. Chinese and Western medicine should build a united front, fighting against superstition and witches together (CQMWA 1950, 72).

Reports of the First National Health Conference (1950)

6. About the issue of Western medicine: scientific medicine was introduced from the West to China, so it is customarily called Western medicine. It is true that this medicine is scientific, and it is this scientific method that resolves many therapeutic problems in China, thus proving the direction of medical transformation in the future. However, most Western doctors in today's China graduated from Western society or from schools of capitalist style. Deeply influenced by the ideology, they somehow accept the capitalist framework without criticism (CQMWA 1950, 22). 
7. The concept of the scientification of Chinese medicine has the following meanings: the first is to learn the elementary knowledge of medical science, such as physiology, anatomy, germs, pathology, contagion. The second is to cooperate with scientists to investigate Chinese medicine, analyze its formula, and identify its properties. It requires basic scientific knowledge to study Chinese acupuncture, explore the clinical experience in ancient China, and facilitate their scientification process (CQMWA 1950, 22).

\section{Reports of the First National Health Conference (1950)}

Example 7 is an official interpretation of the slogan "scientification of Chinese medicine." Nonetheless, although "scientification" is used instead of "westernization" in the first sentence, the elementary knowledge such as anatomy mentioned here is closely related to Western medicine. Those learning this knowledge could be presumed to be Chinese doctors. As can be seen, the second meaning is closer to the real sense of the transformation of traditional Chinese medicine. However, the agency belongs not only to Chinese doctors, as seen in the action "to cooperate with scientists." Two of the most basic definitions of "cooperate" are "act jointly" and "assist someone or comply with their requests." I assume that the second definition describes the current scenario more precisely. Further evidence of the priority of scientists over Chinese doctors is a series of verbs describing the task-“investigate," "analyze," "identify," "study," and "explore," which describe regular work for scientists and not Chinese doctors. In addition, the first and second meanings emphasize two different aspects of the medical issuethe first relates to learning advanced and new knowledge, and the second relates to utilizing prior experiences. It can be inferred that the former is placed in a more-hegemonic position than the latter.

The meaning of "science" and its use in the data differs significantly from the standard definition or typical use in Western contexts. It serves as a demarcation between the modern and advanced, and the backward, feudal, and superstitious, which has special meaning for rural medical work and the construction of a new culture. Moreover, it is frequently used to refer to Western medicine, which, to some extent helps avoid the theoretical wording "westernization of Chinese medicine." What is implied here is that "science" instead of "Western" plays a role in framing and structuring, which is more coherent with the principles of socialist culture. In addition, it should be noted that Mao's ultimate goal for medical work was not to develop two separate branches of medicine but to decrease and eliminate disputes and to integrate the two in a real way. In this sense, the framework for the transformation could only be "science," and not "Western." However, the next section shows that the morality framework for medical work exerts more power than "science" and even constrains "science" to a purely technical level.

\section{The tool and the goal}

This section investigates the way the connotation of "science" was narrowed to the technical level and became inferior to political moral principles, which is first revealed in the frequently occurring word "use." For instance, in example 8, the precondition for absorbing Western or capitalist culture is described by what it can be used for today, 
meaning its actual benefits to the construction of new socialism. In example 9, the modifier of the group including old intellectuals, artists, and doctors is "usable," and they are in a passive position of being "used," "united," "helped," "converted," and "transformed." It can be inferred that the objects in examples 8 and 9 are essentially evaluated as negative since the words "use" and "usable" imply that the thing is deliberately divided into two parts, the positive and the negative, and the manual job is to extract the positive from the negative. This pragmatic method is also considered as characteristic of the discourse of CPC ideology.

8. We should assimilate whatever is useful to us today not only from the present-day socialist and new-democratic cultures but also from the earlier cultures of other nations, for example, from the culture of the various capitalist countries in the Age of Enlightenment (Mao 1986, 397).

On New Democracy (1940)

9. Our task is to unite with all intellectuals, artists, and doctors of the old type who can be useful, to help them, convert them, and transform them (Mao 1991, 1012).

\section{United Front in Cultural Work (1944)}

10. In developing CPC's medical work, we establish the viewpoint of uniting science and the people, and combining technique and revolutionary compassion. The goal of science can be realized only if science is used for the people. Science achieves development only if science is combined with the people (CQMWA 1950, 40).

\section{Reports of the First National Health Conference (1950)}

11. In the Shanxi-Gansu-Ningxia Border Region the human and animal mortality rates are both very high, and at the same time many people still believe in witchcraft. In such circumstances, to rely solely on new doctors is no solution. Of course, new doctors have advantages over old doctors, but if they do not concern themselves with the sufferings of the people, do not train doctors for the people, do not unite with the thousand and more doctors and veterinarians of the old type in the Border Region and do not help them make progress, then they will actually be helping the witch doctors and showing indifference to the high human and animal mortality rates (Mao 1991, 1012).

\section{United Front in Cultural Work (1944)}

Example 10 is an illustration of how the connotation of science was narrowed to the technical level, and how it gives way to political morality. In the first sentence, "science" can be understood as medical knowledge and methods; this element, as well as the skill, is not taken as independent or a sufficient condition for medical work but has to be combined with the morality of "the people" and "revolution." In the second sentence, the goal and prerequisite of scientific development is constructed as a moral one. Example 11 is a description of the severe problems facing medical work in the Border 
Region from Mao's 1944 speech. During that time, Mao still referred to traditional Chinese medicine and Western medicine as "old medicine" and "new medicine," which soon became "Chinese medicine" and "Western medicine." As seen in the second sentence, the relational opposite of "doctors" is a word with explicit political meaning, "people" instead of "patients." Mao insisted that solely relying on new doctors could not solve the problem, and his reasons were laid out in four conditional clauses, which are all negative: "do not concern themselves with the sufferings of the people," "do not train doctors for the people," "do not unite with the thousand and more doctors and veterinarians of the old type in the Border Region," and "do not help them to make progress." Notice that the first conditional clause, "do not concern themselves with the sufferings of the people," makes no sense in real life since most doctors do care about their patients' suffering. Thus, this probably does not address the new doctors' professional morality at all; instead, it functioned as a warm-up for the following three conditional clauses. That is, such professional morality was the necessary and sufficient condition for new doctors to unite with doctors of traditional Chinese medicine. In this way, the moral principle of socialism was mingled with professional morality as both a political and a moral appeal.

In fact, the way the connotation of "science" was narrowed to a technical level was not new in Mao's period; rather, it was the product of a long-debated issue after the Sino-Japanese War (1894-1895) when China, for the first time in history, went through deep crisis regarding indigenous culture. A typical example is the slogan "Chinese ideology and Western applied science," which acted as the ideological framework for the Self-Strengthening movement from 1861 to 1895 . Framing Western culture as a mere technical concept ensured that the only aspect of that culture to be absorbed was technology, and local culture would not be seriously threatened. Through such use, in the discourse of medical policy, the fundamental differences between Chinese and Western medicine were ultimately technical, not cultural, and the party's revolutionary morality of "serving the people" served as the ideological framework. This way of separating the technical from the moral can also be found in the metaphor in Mao's speech "On Democratic Culture," discussed in the next section.

\section{The dialectical method in cultural issues}

This section further investigates the method of separating the ideological or cultural discourse from Western culture and Western medicine by analyzing the central metaphor "culture as food" in Mao's speech.

12. To nourish her own culture China needs to assimilate a good deal of foreign progressive culture, not enough of which was done in the past. We should assimilate whatever is useful to us today not only from the present-day socialist and new democratic cultures but also from the earlier cultures of other nations, for example, from the culture of the various capitalist countries in the Age of Enlightenment. However, we should not gulp any of this foreign material down uncritically, but must treat it as we do our food-first chewing it, then submitting it to the working of the stomach and intestines with their juices and secretions, and separating it into nutriments to be absorbed and waste matter to be discarded-before it can nourish 
us. To advocate "wholesale westernization" is wrong. China has suffered a great deal from the mechanical absorption of foreign material (Mao 1986, 397).

On New Democracy (1940)

Researchers often cite the metaphor in this example as a lens through which to investigate Mao's thoughts about Chinese and Western cultures. Interestingly, advanced Western culture was analogous to raw material instead of edible food, suggesting that the culture abroad had to be transformed first, just as raw material must be cooked to be real food. This metaphor constructed pragmatism such that Western culture was classified into two parts, and only the part coherent with Chinese socialism culture was chosen. For instance, Western culture, which is "progressive" and "useful," is defined and includes the cultures of the various capitalist countries in the Age of Enlightenment. Moreover, in the metaphor, the digestive process is divided into several steps. First, the process of accepting and taking in Western culture is compared with the activity of chewing in the mouth and swallowing food into stomach. Then, during the digestive process, the saliva and gastric juices break down the food into either nutriments or waste. The waste is then excreted and discarded, and the nutriments are absorbed. In fact, this is not a natural process of our body's functions since it overstates the control our body has by emphasizing the classification, selection, and treatment of food inside the body, when the only chance to make such choices is when food stays in our mouths.

Therefore, the "culture as food" metaphor legitimized the process of the selection and transformation of Western culture in that it naturalized the part of a coherent culture that was separated into good and bad, useful and useless, guaranteeing that only the good and useful would be absorbed. One of the most difficult parts of learning from the West was that on the one hand, Chinese modernization needs the advanced technology and theories, but on the other hand, assimilating capitalist ideology would be detrimental to the coherence of socialism. In this way, both the traditional local traditions and Western culture were broken down, and the suitable elements were selected, integrated, and transformed into a new system to serve socialist society. The same process applied to the development of medicine.

\section{Conclusions}

The above analysis explores how the cultural dilemma in the policy discourse of traditional Chinese medicine from 1940 to 1950 was proposed, approached, and tentatively solved. It is found that Chinese traditional medicine was taken as the remnant of deep-rooted feudalism, and Western medicine was constructed as a symbol of imperialism. Therefore, traditional Chinese medicine needed to learn from Western medicine in terms of technical aspects, but the transformation of moral aspects was emphasized for both Western and traditional Chinese medicine. In the last section, this tension or dilemma was investigated through the linguistic uses in the data. The term "science" was used in opposition to feudalism and superstition, which is very different from the definition in Western contexts. In addition, various attempts were made to avoid the abstraction "westernization of Chinese medicine" and guarantee that the transformation was under a framework of "science" but not "Western." For instance, the term "scientific medicine" was frequently used to refer to Western medicine to extract the spatial 
location from the social ideology. Furthermore, this scientific framework gave way to a political moral framework by narrowing the connotation of "science" to a purely technical level. Separating the ideological and cultural discourse from Western culture and Western medicine was also considered a method of pragmatism, which is further investigated in detail through the analysis of the central metaphor "culture as food" in Mao's speech. This legitimized the process of dividing Western culture into two parts and taking advantage of certain aspects, ensuring that technology was the only aspect to be absorbed and local culture would not be seriously threatened. As a result, what is drawn from the analysis is not only the competing ideological factors underlying traditional Chinese medicine and Western medicine but also, and more significantly, the attempt to maintain a delicate balance between them in the discourse since these contradictions needed to be carefully approached before the policy could eventually be solidified. Linguistic choices including word meaning, word use, grammar, and metaphors demonstrate this attempt, since choosing one instead of the other always has implications.

Neither this tension nor the linguistic representation of such tension is new or unique to the CPC discourse. In this study, the tension is further understood from the perspective of habitus. For instance, as illustrated in the analysis, the interpretation of "science" under the framework of modernization and nationalism began in the late Qing dynasty. Similarly, the way that the connotation of "science" was narrowed to the technical level and became inferior to political moral principles as well as the metaphor of culture as food can be perceived as a recontextualization of the debate about learning from Western culture in Chinese history. Indeed, by paying more attention to China's semi-colonial and semi-feudal history for over 100 years, it is much easier to understand both of these inclinations and their contradictions. In an ancient culture with an extremely solid framework of Confucianism, the modernization process is not initiated from inside but forced by outside factors. Since integrating foreign culture would unavoidably threaten the local culture, addressing the relationship of the two cultures becomes a perpetual problem in Chinese society, as well as in the Chinese discourse on cultural issues.

It should be noted that this analysis has its limitations. The concept of continuity in this study is largely taken as a presumption rather than based on more solid analysis. To accomplish such an analysis would require a much larger quantity of data and background information as well as the analysis of intertextual and interdiscursive relationships between discourses in different historical periods. The same problem exists with the loosely proposed concepts of cultural habitus. That said, I believe that future research will not only be illuminating for studying the history of Chinese medicine, but more importantly, may lead to meaningful discussion on Chinese culture.

\section{Endnotes}

${ }^{1}$ The database in this study includes 64,372 Chinese characters. The translations of "On New Democracy" and "United Front in Cultural Work" were based on published English versions with minor revisions. For the translation of data, the separation of the sentences in English does not follow Chinese grammar in which a sentence can be connected by a comma without conjunctions but still function as a complete sentence. Additionally, "traditional Chinese medicine" and "Western medicine" are taken as general terms that are still commonly used today. The references to "Western doctor" and "Chinese doctor" refer to doctors of Western medicine and doctors of traditional Chinese medicine respectively. 
Abbreviations

CDA: Critical discourse analysis; CPC: Communist Party of China

\author{
Acknowledgements
}

Not applicable.

Funding

Not applicable.

\title{
Availability of data and materials
}

Not applicable.

\section{Author's contributions}

The author conducted all stages of this research. The author read and approved the final manuscript.

\section{Competing interests}

The author declares that she has no competing interests.

\section{Publisher's Note}

Springer Nature remains neutral with regard to jurisdictional claims in published maps and institutional affiliations.

Received: 27 July 2018 Accepted: 24 January 2019

Published online: 08 February 2019

\section{References}

Bai, L.X. 1992. Chinese nationalism and modernization. Twenty-First Century 9: 13-26.

Bourdieu, P. 1990. The logic of practice. Stanford: Stanford University Press.

Bourdieu, P., and L.J.D. Wacquant. 1992. An invitation to reflexive sociology. Cambridge: Polity Press.

Chouliaraki, L., and N. Fairclough. 1999. Discourse in late modernity: Rethinking critical discourse analysis. Edinburgh: Edinburgh University Press.

CQMWA. 1950. Important documents in the first national health conference. Chongqing: CQMWA Press.

Croizier, R.C. 1968. Traditional medicine in modern China: Science, nationalism and the tensions of cultural change. Cambridge: Harvard University Press.

Ding, M.B. 1993. Study on Mao Zedong's Health Policy. Wuhan: Hubei Science and Technology Press.

Fairclough, N. 1989. Language and power. London: Longman.

Fairclough, N. 1992. Discourse and social change. Cambridge: Polity Press.

Fan, J.H. 2014. The research of the historic forming process of the policy 'Unity of Traditional Chinese medicine and Western medicine.'. In Masters thesis, Guangzhou University of Chinese Medicine.

Farquhar, J. 1994. Knowing practice: The clinical encounter of Chinese medicine. Boulder: Westview Press.

Forchtner, B., and C. Schneickert. 2016. Collective learning in social fields: Bourdieu, Habermas and critical discourse studies. Discourse \& Society 27 (3): 293-307.

Jia, D.D. 1978. Chinese medical history. Beijing: People's Medical Publishing House.

Jin, G.T., and Q.F. Liu. 2009. Study on history of concepts. Beijing: Law Press.

Lampton, D.M. 1974. Health policy during the great leap forward. China Quarterly 60: 668-699.

Li, J.W. 1986. History of Chinese medical work during revolutionary war. Journal of Traditional Chinese Medicine 322(8): 52-56.

Li, J.W. 1998. A Chinese foreign exchange history of medicine. In Changsha: Hunan Education Publishing House.

Li, J.W., and Z.F. Cheng, eds. 1987. Chinese medical history. Shanghai: Shanghai Scientific \& Technical Publishers.

Liang, Q.C. 1989. Ice-drinking room combined collected works. Vol. 4. Beijing: China Publishing House.

Liu, J.J. 2014. Investigation of Mao Zedong's Chinese medical thoughts. Journal of Chifeng University (Philosophy and Social Science Chinese Edition) 35 (2): 89-91.

Mao, Z.D. 1986. Selected readings from the works of MAO TSETUNG. Beijing: Chinese People's Publishing House.

Mao, Z.D. 1991. Selected works of Mao Zedong. Vol. 3. Beijing: Chinese People's Publishing House.

Mao, Z.D. 2013. The chronicle of Mao Zedong's life (1949-1976). Beijing: Central Party Literature Press.

Scheid, V. 2002. Chinese medicine in contemporary China. Durham: Duke University Press.

Sivin, Nathan. 1987. Traditional medicine in contemporary China. Ann Arbor: University of Michigan.

Sun, L.C. 1998. Series studies on Mao Zedong's medical thoughts. Beijing: People's Medical Publishing House.

Taylor, K. 2005. Chinese medicine in early communist China, 1945-63. New York: Taylor \& Francis Routledge.

Unger, J.W. 2013. The discursive construction of the scots language. Amsterdam: John Benjamins B. V.

Unschuld, P.U. 1985. Medicine in China: A history of ideas. Berkeley: University of California Press.

Van Dijk, T.A. 1998. Ideology: A multidisciplinary approach. London: SAGE.

Wang, F.W., L.P. Chen, J. Hu, and G. Zhang. 2011. Use of traditional Chinese medicine during the red Army period in Chinese history. Journal of Chinese Integrative Medicine 10: 1145-1149.

Wang, H. 2004. China from empire to nation-state. Beijing: SDX Joint Publishing Company.

Wang, L.N., and Y.F. Tao. 1996. Mao's thoughts and the formation and development of the policy 'combining Chinese and Western medicine. Theory Journal 1: 31-33.

Wen, J.T. 2010. Analysis of cooperation between Chinese and Western medicine in Ningxia Border Region during the war of resistance against Japan (1937-1945). The Journal of Studies of China's Resistance War Against Japan 4: 114-121.

Williams, R. 1983. Keywords: A vocabulary of culture and society. New York: Oxford University Press.

Wodak, R. 2001. The discourse-historical approach (DHA). In Methods of critical discourse analysis, ed. R. Wodak and M. Meyer, 2nd ed., 63-94. London: SAGE. 
Wodak, R. 2011. The discourse of politics in action: Politics as usual. New York: Palgrave Macmillan.

Wodak, R., R. de Cillia, M. Reisigl, et al. 2009. The discursive construction of National Identity. Edinburgh: Edinburgh University Press.

Wodak, R., and N. Fairclough. 2010. Recontextualizing European higher education policies: The cases of Austria and Romania. Critical Discourse Studies 7 (1): 19-40.

Zhao, H.J. 1989. Modern history of Chinese and Western medicine. Anhui: Anhui Science and Technology Press.

Zhu, H.Z. 2010. Beginning and end of movement 'cooperation between Chinese and Western medicine' in Yan'an. Memories and Archives 5: 22-26.

Submit your manuscript to a SpringerOpen ${ }^{\circ}$ journal and benefit from:

- Convenient online submission

- Rigorous peer review

- Open access: articles freely available online

- High visibility within the field

- Retaining the copyright to your article

Submit your next manuscript at $\boldsymbol{\nabla}$ springeropen.com 